\title{
The rpg4-Mediated Resistance to Wheat Stem Rust (Puccinia graminis) in Barley (Hordeum vulgare) Requires Rpg5, a Second NBS-LRR Gene, and an Actin Depolymerization Factor
}

\author{
X. Wang, ${ }^{1}$ J. Richards, ${ }^{1}$ T. Gross, ${ }^{1}$ A. Druka, ${ }^{2}$ A. Kleinhofs, ${ }^{3}$ B. Steffenson, ${ }^{4}$ M. Acevedo, ${ }^{1}$ and \\ R. Brueggeman ${ }^{1}$ \\ ${ }^{1}$ Department of Plant Pathology, North Dakota State University, Fargo 58108, U.S.A.; ${ }^{2}$ The James Hutton Institute, \\ Invergowrie, Dundee DD2 5DA, Scotland, U.K.; ${ }^{3}$ Department of Crop and Soil Science, Washington State University, \\ Pullman 99164, U.S.A.; ${ }^{4}$ Department of Plant Pathology, University of Minnesota, St. Paul 55108, U.S.A.
}

Submitted 7 June 2012. Accepted 20 November 2012.

\begin{abstract}
The rpg 4 gene confers recessive resistance to several races of wheat stem rust (Puccinia graminis f. sp. tritici) and Rpg5 provides dominant resistance against isolates of the rye stem rust ( $P$. graminis f. sp. secalis) in barley. The rpg4 and Rpg5 genes are tightly linked on chromosome $5 \mathrm{H}$, and positional cloning using high-resolution populations clearly separated the genes, unambiguously identifying Rpg5; however, the identity of rpg4 remained unclear. High-resolution genotyping of critical recombinants at the rpg4/Rpg5 locus, designated here as rpg4-mediated resistance locus (RMRL) delimited two distinct yet tightly linked loci required for resistance, designated as RMRL1 and RMRL2. Utilizing virus-induced gene silencing, each gene at RMRL1, i.e., HvRgal (a nucleotide-binding site leucine-rich repeat [NBSLRR] domain gene), Rpg5 (an NBS-LRR-protein kinase domain gene), and $H v A d f 3$ (an actin depolymerizing factor-like gene), was individually silenced followed by inoculation with $P$. graminis f. sp. tritici race QCCJ. Silencing each gene changed the reaction type from incompatible to compatible, indicating that all three genes are required for rpg4-mediated resistance. This stem rust resistance mechanism in barley follows the emerging theme of unrelated pairs of genetically linked NBS-LRR genes required for specific pathogen recognition and resistance. It also appears that actin cytoskeleton dynamics may play an important role in determining resistance against several races of stem rust in barley.
\end{abstract}

Sequence data referred to in this article are deposited in the GenBank database. The following sequences were previously deposited by Brueggeman and associates (2008): accession numbers EU812563 (genomic sequence from barley 'Morex'), EU878778 (genomic sequence from barley line 'Q21861'), EU883581 to EU883583 (HvRGA1genomic sequence from barley lines 'Harrington', 'MD2', and 'Steptoe', respectively), EU883788 to EU883790 (rpg5 allele [HvRGA2] genomic sequence from barley lines Harrington, MD2, and Steptoe, respectively), and EU883791 (HvAdf3 genomic sequence from barley line Steptoe)].

Corresponding author: R. Brueggeman; Telephone: +1.701.231.7078; Fax: +1.701.231.7851; E-mail: Robert.Brueggeman@ndsu.edu

* The $e$-Xtra logo stands for "electronic extra" and indicates that one supplementary figure and one supplementary table are published online.

C 2013 The American Phytopathological Society
Stem rust epidemics in barley (Hordeum vulgare) can be caused by two biotrophic fungal pathogens, Puccinia graminis f. sp. tritici, the wheat stem rust fungus, and Puccinia graminis f. sp. secalis, the rye stem rust fungus. Prior to the $1950 \mathrm{~s}$, wheat stem rust was a devastating disease of barley and wheat in the upper midwestern states of the United States and prairie provinces of Canada until management was achieved by the deployment of genetic resistance. The single dominant Rpgl resistance gene has exclusively protected Midwestern barley cultivars against stem rust for nearly 70 years - a remarkable durability for otherwise easily breakable rust resistances (Steffenson 1992). However, during the 1989 growing season, a new race of $P$. graminis $\mathrm{f}$. sp. tritici, named QCCJ, was identified in North Dakota (Roelfs et al. 1991) as being virulent on barley cultivars containing Rpgl. The Rpgl virulence raised concern that Midwestern barley production would experience the return of stem rust epidemics, prompting a search for resistance genes against this pathogen (Jin et al. 1994a).

The barley line 'Q21861', originally from the International Maize and Wheat Improvement Center, was identified as highly resistant to stem rust race QCCJ. The recessive and temperaturesensitive $P$. graminis $\mathrm{f}$. $\mathrm{sp}$. tritici race QCCJ resistance was mapped to the telomeric region of the long arm of barley chromosome 5H and designated as the rpg4 locus (Borovkova et al. 1995; Jin et al. 1994b). Q21861 also carries resistance against the rye stem rust ( $P$. graminis f. sp. secalis) isolate $92-\mathrm{MN}-90$, designated Rpg5, which also mapped to chromosome 5H, cosegregating with rpg4 in a low-resolution mapping population (Sun et al. 1996). However, analysis of a 'Steptoe' (susceptible) $\times$ Q21861 high-resolution population identified five recombinant lines with rpg4 and Rpg5 segregating, indicating that the genes were distinct (Brueggeman et al. 2008).

A current threat to barley and wheat production worldwide and potential threat to production in North America is stem rust race TTKSK (aka Ug99) and its variants. Race TTKSK was first reported from Uganda, Africa in 1999 (Pretorius et al. 2000). It is considered to be a major threat to world food security because it is virulent on over $97 \%$ of barley cultivars worldwide (Steffenson et al. 2012), including those having Rpg1 (Steffenson and Jin 2006), and approximately $70 \%$ of the world's wheat cultivars (Singh et al. 2008). Fortunately, the rpg4 resistance locus previously characterized and cloned (Brueggeman et al. 2008) confers a high level of resistance against TTKSK (Steffenson et al. 2009). 
Plant resistance $(R)$ genes, representing innate receptors that identify and impart race-specific resistance against host-specific pathogens, have been cloned from many plant species. Prediction of the protein structures encoded by the $>70$ cloned $R$ genes, effective against a wide taxonomical range of pathogens, has shown that most fall into well-defined structural classes, with the major class coding for nucleotide-binding site (NBS) and leucine-rich repeat (LRR) domain proteins (Martin et al. 2003). The second major class encodes proteins that contain at least one serine/threonine protein kinase (STPK) domain (Martin et al. 2003).

The NBS-LRR genes make up the largest family of plant disease resistance genes, with 159 homologous sequences present in the Arabidopsis genome (Meyers et al. 2003) and 535 present in the rice genome (Zhou et al. 2004). NBS-LRR genes are frequently clustered as complex loci in the plant genomes, typically containing several copies of duplicated genes with high homology one to another, as well as including NBSLRR genes from different gene families that share little or no sequence homology (Hulbert et al. 2001; Leister 2004). These complex loci commonly confer resistance to specific isolates or races of a pathogen, presumably in a gene-for-gene relationship, implying a single dominant gene at the locus conferring resistance (Flor 1971). However, it has been demonstrated for nine resistances mechanisms in both model plants and agronomically important crops that two unrelated NBS-LRR genes are required to function together against specific races or isolates of the corresponding pathogen (Ashikawa et al. 2008; Birker et al. 2009; Lee et al. 2009; Loutre et al. 2009; Narusuka et al. 2009; Okuyama et al. 2011; Peart et al. 2005; Sinapidou et al. 2004; Yuan et al. 2011). Typically, the two NBS-LRR genes required for resistance in such systems are genetically linked. The one possible exception could be the tobacco $\mathrm{N}$ and NRG1 genes required for Tobacco mosaic virus resistance but this could simply be due to the lack of genetic linkage data or chromosome positions (Peart et al. 2005). The emerging theme of dual NBS-LRR resistance genes operating in concert for pathogen recognition to activate host-cell defense responses appears to be a common feature of plant innate immune systems.

$\mathrm{R}$ proteins are presumed to detect pathogen challenge through direct protein-protein interaction with pathogen avirulence (AVR) proteins. However, direct interaction between $\mathrm{R}$ proteins and their corresponding AVR proteins has been demonstrated for relatively few interactions, where both the host $R$ gene and pathogen $A v r$ gene or genes have been identified (Deslandes et al. 2003; Dodds et al. 2006; Jia et al. 2000; Ueda et al. 2006). Some NBS-LRR R proteins are modular and protein fragments have been shown to be sufficient for initiation of defense signaling (Eitas and Dangl 2010). This modular activity, in conjunction with the requirement of two or more $\mathrm{R}$ proteins in a resistance complex, suggests that pathogen recognition possibly requires different combinations of domains from distinct proteins. The domain combinations of interacting $\mathrm{R}$ proteins (i.e., NBS-LRR and STPK) in addition to the guard model (Van Der Biezen and Jones 1998) and NBS-LRR proteins functioning in downstream signaling pathways (Caplan et al. 2008) may explain why most yeast two-hybrid experiments fail to detect direct $\mathrm{R}$ protein-Avr protein interactions.

$R$-gene-mediated detection of the pathogen activates signal transduction pathways involving phosphorylation cascades via the STPK. The STPK domains containing $R$ proteins confer resistance to bacterial and fungal pathogens, and have been identified in a wide range of plant species (Brueggeman et al. 2002, 2008; Fu et al. 2009; Martin et al. 1993; Song et al. 1995; Sun et al. 2004; Swiderski and Innes 2001). The presence of STPK domains in this major class of $R$ genes suggests involvement in signaling cascades through phosphorylation activity
(Hanks et al. 1988). However, STPK domains have also been shown to interact directly with AVR proteins, demonstrating the ability to recognize pathogen effectors through protein-protein interactions (Tang et al. 1996). In Arabidopsis, resistance against Pseudomonas syringae strains that carry $A v r P p h B$ require two genes: RPS5, an NBS-LRR gene, and PBS1, an STPK (Swiderski and Innes 2001). The RPS5 immune receptor constitutively binds to the PBS1 effector target guarding the protein by detecting AvrPphB-specific cleavage of PBS1 (Van der Hoon and Kamoun 2008; Shao et al. 2003). The perception of PBS1 cleavage signals RPS5 to activate effector-triggered immunity (ETI). Some cytosolic STPK may serve as decoys and the interactions with the cognate effector triggers ETI but the true STPK effector target may be a protein involved in pathogen-associated molecular pattern (PAMP)-triggered immunity (PTI) (Block and Alfano 2011). It has been shown that the $A v r P p h B$ interaction with PBS1 may be a decoy-effector interaction guarded by RPS5 and the real effector target is the BIKI STPK that interacts with the PAMP-recognition receptor FLS2. (Block and Alfano 2011). The RPS5/PBS1-mediated resistance also has been shown to require an actin depolymerization factor, AtADF4, for resistance (Tian et al. 2009).

ADF proteins, in concert with other actin-binding proteins, regulate actin filament dynamics leading to cytoskeleton rearrangement. Plant ADF proteins have been shown to play roles in biotic (Miklis et al. 2007; Tian et al. 2009) and abiotic stress responses (Ouellet et al. 2001), root formation (Thomas and Schiefelbein 2002), and pollen tube growth (Chen et al. 2003). However, there is little information regarding the molecular mechanisms underlying these dynamic responses to environmental or developmental stimuli. Plant genomes have limited numbers of $A d f$ genes, as demonstrated by the presence of only $12 A d f$ genes in the sequenced genomes of Arabidopsis and rice (Feng et al. 2006). Minimal redundancy suggests that individual $A d f$ genes, although having concise function, are probably differentially modulated by diverse biotic, abiotic, and developmental stimuli, involving phosphorylation and dephosphorylation-dependent signaling.

The Arabidopsis thaliana gene, AtAdf4, was recently shown to be required for $R P S 5 / P B S 1$-mediated resistance against $P$. syringae harboring the effector AvrPphB (Tian et al. 2009). Previous research had determined that cytoskeleton reorganization was a characteristic basal resistance or nonhost resistance response (Kwon et al. 2008), with limited circumstantial evidence supporting its role in specific or $R$-gene-mediated resistance. Tian and associates (2009) demonstrated that AtAdf4 was required for RPS5-initiated defense signaling but was not involved in what is considered to be the hallmark event of nonhost resistance: cytoskeleton polarization leading to callose deposition and resistance against pathogen entry at the cell periphery.

Previously, we had reported that the $H v$ Adf2 gene at the rpg4/Rpg5 locus was a candidate rpg4 gene (Brueggeman et al. 2008, 2009); however, the research reported here eliminates HvAdf2 as a candidate gene and shows that rpg4-mediated resistance is a complex system requiring the concerted action of several genes at the locus. The high-resolution mapping of resistance against Puccinia graminis f. sp. tritici race QCCJ identified two distinct, yet tightly linked loci required for wheat stem rust resistance: rpg4-mediated resistance locus (RMRL) 1 and RMRL2 (Fig. 1). The loci were genetically delimited to physical regions of approximately 70 and $220 \mathrm{kbp}$, respectively (Fig. 2). Post-transcriptional gene silencing using Barley stripe mosaic virus (BSMV) virus-induced gene silencing (VIGS) determined that RMRL1 contains three genes required together for P. graminis f. sp. tritici race QCCJ resistance: the NBS-LRR gene $H v$ Rga1, the NBS-LRR-STPK gene Rpg5, and the actin depoly- 
merizing factor-like gene, $H v$ Adf3. Silencing each gene present at RMRL1 resulted in a shift from incompatibility to compatibility in the resistant barley line Q21861. Our data demonstrate that $P$. graminis f. sp. tritici race QCCJ stem rust resistance is conferred by a complex locus requiring the interaction of at least four tightly linked genes and that the system follows the emerging theme of two tightly linked yet unrelated NBS-LRR genes for resistance against a specific pathogen.

\section{RESULTS}

\section{Recombinant analysis.}

Previous efforts to clone the rpg4 and Rpg5 genes resulted in the development of three high-resolution mapping populations ('Harrington' $\times$ Q21861 [HQ], 'Multidominant 2' × Q21861 [MD2Q], and Steptoe $\times$ Q21861 [SQ]), representing a total of 5,223 recombinant gametes (Brueggeman et al. 2008). The populations were developed by crossing the stem rust-resistant line Q21861, known to carry Rpg1, rpg4, and Rpg5, with three different susceptible parents (Harrington, 'MD2', and Steptoe). Positional cloning based on these populations and a 'Morex' barley bacterial artificial chromosome (BAC) library (Yu et al. 2000) resulted in the identification of the Rpg5 gene encoding an NBSLRR-STPK protein conferring resistance to the $P$. graminis $\mathrm{f}$. $\mathrm{sp}$. secalis isolate $92-\mathrm{MN}-90$. This positional cloning analysis also identified a candidate $r p g 4$ gene, $H v$ Adf 2 , encoding a putative actin depolymerizing factor protein (Brueggeman et al. 2008, 2009). This result was not conclusive because there were genetic data indicating that resistance against $P$. graminis f. sp. tritici races QCCJ and TTKSK also required the Rpg5 locus, and the SQ population contained a single recombinant (SQ55) that did not corroborate HvAdf2 as the rpg4 gene (Fig. 1).
Further analysis with new molecular markers of 14 recombinants within or closely flanking the rpg4/Rpg5 locus, now designated RMRL, showed that the SQ population segregated for an additional tightly linked locus required for wheat stem rust resistance, now designated RMRL2, that contained a gene that was not functionally polymorphic in the HQ and MD2Q crosses (Fig. 1). Lines defining RMRL (HQ1, HQ9, HQ18, SQ31, SQ41, SQ44, SQ46, SQ47, SQ48, and SQ55) were backcrossed to the parental lines that were not contributing to the genotype or phenotype at the loci. Homozygous plants for RMRL were selected after each round of backcrossing using marker-assisted selection with the Rpg5+ (Rsts1) and rpg5(Psts1) markers (Supplementary Table S1). The selected $\mathrm{BC}_{2} \mathrm{~F}_{3}$ and $\mathrm{BC}_{3} \mathrm{~F}_{3}$ recombinant lines were infected with $P$. graminis $\mathrm{f}$. sp. tritici races QCCJ and TTKSK and their rust reactions assayed (Table 1). This, in combination with the genotype analysis using single-nucleotide protein (SNP) and sequence tag site (STS) markers, allowed identification of two distinct yet tightly linked loci, RMRL1 and RMRL2, required for resistance to $P$. graminis f. sp. tritici races QCCJ and TTKSK (Figs. 1 and 2).

Analysis of the SQ population delimited $P$. graminis f. sp. tritici race QCCJ resistance (rpg4-mediated resistance) to the distinct RMRL2, located up to $220 \mathrm{kbp}$ distal of the genetically defined RMRL1 (Fig. 2). Five P. graminis f. sp. tritici race QCCJ- and TTKSK-susceptible SQ recombinant lines (SQ31, SQ41, SQ47, SQ48, and SQ55) all had the Q21861 (resistant) genotype at the RMRL1 delimited by markers ARD5112 and Rsnp.1, with recombination occurring at or near to the HvAdf2 gene, and the Steptoe (susceptible) genotype distal of the SNP markers Rsnp.1 or Rsnp.2 (Fig. 1). The QCCJ- and TTKSK-susceptible recombinant line SQ55 had

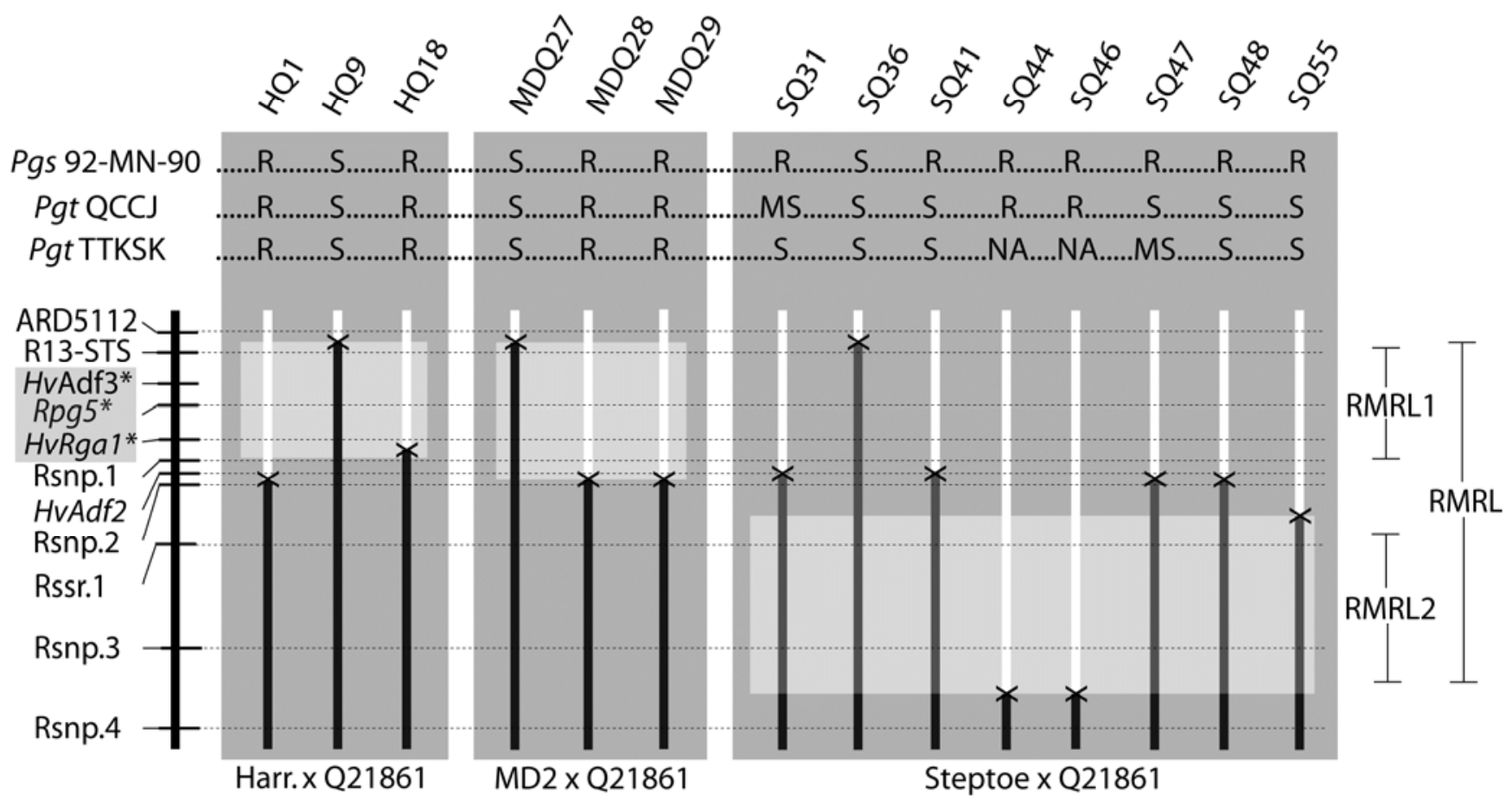

Fig. 1. High-resolution analysis of recombinants genetically defining the rpg4/Rpg 5 locus. The general reactions of recombinant lines, designated at the top, to wheat stem rust races QCCJ and TTKSK or rye stem rust isolate 92-MN-90, are shown (R is resistant, MR is moderately resistant, MS is moderately susceptible, $\mathrm{S}$ is susceptible, and NA is data not available). The vertical black bar on the left represents a physical map developed using the 'Morex' bacterial artificial chromosome (BAC) sequence (GenBank accession number EU812563) and restriction mapping of unsequenced BACs 64h24 and 259b20. The order of genetic markers and candidate genes required for rpg4-mediated resistance are labeled to the left, with candidate genes designated with an asterisk. Recombinant designations are given above the vertical bars representative of the genotypes of each recombinant defined by the genetic markers and genes to the left. White depicts Q21861 (resistant) genotype and black or dark gray represents the respective susceptible genotypes, with black Xs showing the approximate region of recombination. Internal boxed regions represent the loci delimiting rpg4-mediated resistance in each population designated below. Bars to the right depict the regions delimiting the rpg4-mediated resistance locus (RMRL) and the RMRL1 and RMRL2 subloci. 
the Q21861 genotype extending the farthest distally, with recombination occurring distal of the genetic marker Rsnp.2, positioning RMRL2 at least $1 \mathrm{kbp}$ distal of the $H v A d f 2$ gene (Figs. 1 and 2). The P. graminis f. sp. tritici race QCCJresistant lines SQ44 and SQ46 had the Q21861 genotype extending distal to Rsnp.3 with recombination and the Steptoe genotype proximal of Rsnp.4; thus, Rsnp.4 flanks RMRL2 on the distal side (Figs. 1 and 2). The RMRL2 was defined by the markers Rsnp.4 and Rsnp.2, delimiting an approximately 220 kbp physical region (Fig. 2), and contains yet-to-be-identified genes required for rpg4-mediated resistance designated rpg4 modifier element 1 (Rme1). This physical region is present on the Morex BAC clones 64H24, 259B20, and 543P19 (Fig. 2B).

Phenotyping of the HQ and MD2Q populations with $P$. graminis f. sp. tritici races QCCJ and TTKSK identified resistant recombinant lines (HQ1, HQ18, MD2Q28, and MD2Q29) with the Q21861 genotype at RMRL1 and the susceptible par- ent genotypes at RMRL2, showing that the susceptible parents Harrington and MD2 must contain an Rme1 allele that is functional for stem rust resistance (Fig. 1). These resistant HQ and MD2Q recombinant lines with susceptible parent genotypes distal of the markers Rsnp.1 and Rsnp. 2 indicated that, in addition to RMRL2 identified in the SQ population, other genes located at RMRL1 are also required for resistance against $P$. graminis f. sp. tritici races QCCJ and TTKSK (Fig. 1). The genotypic and phenotypic analysis of the recombinant lines from the HQ and MD2Q populations identified recombinants from each population delimiting resistance to $P$. graminis $\mathrm{f}$. $\mathrm{sp}$. tritici races QCCJ and TTKSK (HQ18, HQ9, MD2Q27, and MD2Q28). The RMRL1 regions required for wheat stem rust resistance in the HQ and MD2Q populations were identical to the approximately $70-\mathrm{kbp}$ region delimiting Rpg5-mediated resistance against the rye stem rust isolate $92-\mathrm{MN}-90$ (Fig. 1). The marker R13-STS delimits RMRL1 proximally for both

A genetic maps

Chromosome $5 \mathrm{H}$ RMRL

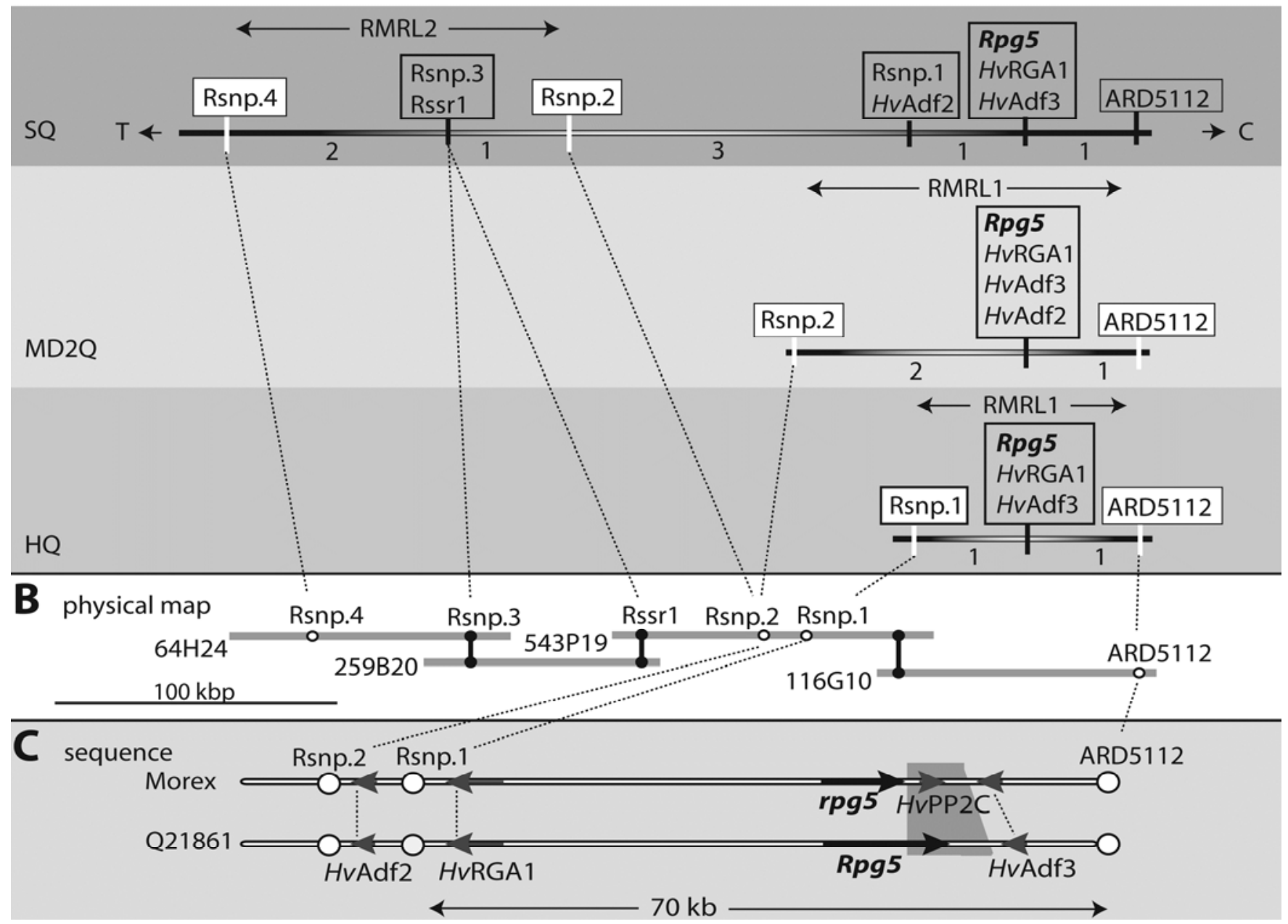

Fig. 2. Genetic maps, physical map, and sequence annotation of the rpg4/Rpg5 region. A, Genetic maps from the three individual crosses ('Steptoe' $\times$ 'Q21861' [SQ], 'Multidominant 2' $\times$ Q21861 [MD2Q], and 'Harrington' $\times$ Q21861 [HQ]) used in the analysis are shown. Genetic markers and candidate genes are surrounded by boxes. White boxes indicate markers delimiting the regions required for Puccinia graminis f. sp. tritici QCCJ resistance (rpg4), also represented by the horizontal double-headed arrows. The number of recombinants identified between markers is shown below the horizontal bar representing the genetic region and the $\mathrm{T}$ and $\mathrm{C}$ indicate direction of the telomere and centromere, respectively. B, 'Morex' bacterial artificial chromosome (BAC) contig clones are represented by horizontal gray bars labeled to the left. Molecular markers delimiting the two regions required for $P$. graminis f. sp. tritici QCCJ (rpg4)-mediated resistance are shown as white circles. Black circles indicate positions of annotated genes and molecular markers. C, Sequence and gene annotation of Morex BAC clones (above) and Q21861-sequenced regions (below) are shown as horizontal bars. The region represents the approximately 70 $\mathrm{kbp}$ required for P. graminis f. sp. tritici race QCCJ (rpg4-mediated) resistance delimited in the HQ population. Annotated genes are represented as arrows with gene designations. The scale is shown in kilobase pairs $(\mathrm{kb})$. 
populations and, for the MD2Q population, the locus is delimited on the distal side by the marker Rsnp.2; however, for the HQ population, RMRL1 is delimited distally by Rsnp.1 (Figs. 1 and 2). Thus, the smallest region required for resistance to $P$. graminis $\mathrm{f}$. sp. tritici races QCCJ and TTKSK was delimited in the HQ population by the recombinants HQ18 and HQ9 corresponding to an approximately 70-kbp physical region. Three cosegregating genes ( $H v$ Rga1, Rpg5, and HvAdf3) in the region were considered as candidate genes required for resistance against wheat stem rust races QCCJ and TTKSK (Figs. 1 and 2).

\section{Gene annotation and protein domain structures.}

The Rpg5 gene codes for a 1,378-amino acid (aa) (151.6 $\mathrm{kDa}$ ) protein that contains the NBS, LRR, and STPK predicted protein domains (Brueggeman et al. 2008). Allele analysis showed that all the susceptible parents contain a nonfunctional Rpg5 allele, with either an in-frame stop codon leading to a truncated protein or the STPK domain missing, as in susceptible Harrington, Morex, and Steptoe (Fig. 3). In these barley cultivars, the STPK domain was replaced by a protein phosphatase $2 \mathrm{C}$ gene, designated $H v \mathrm{PP} 2 \mathrm{C}$, presumably by an insertion/deletion event (Figs. 2C and 3).

The HvRgal gene codes for an 895 -aa $(98.5-\mathrm{kDa})$ protein predicted to contain the typical NBS-LRR resistance-like protein domain structure. A BLAST n sequence homology comparison between the $H v$ Rgal and Rpg 5 genes using low stringency determined that the two genes, although belonging to similar classes of NBS-LRR domain containing resistance pro-

Table 1. Infection types (IT) of parental lines and recombinants in response to pathotypes of Puccinia graminis $\mathrm{f}$. sp. tritici and an isolate of P. graminis $\mathrm{f}$. sp. secalis at the seedling stage ${ }^{\mathrm{a}}$

\begin{tabular}{|c|c|c|c|c|c|c|}
\hline \multirow[b]{3}{*}{ Line } & \multicolumn{4}{|c|}{ Pathotype } & \multirow{2}{*}{\multicolumn{2}{|c|}{$\begin{array}{c}\text { Isolate } \\
\text { 92-MN-90 }\end{array}$}} \\
\hline & \multicolumn{2}{|c|}{ QCCJ } & \multicolumn{2}{|c|}{ TTKSK } & & \\
\hline & IT-M & GR & IT-M & GR & IT-M & GR \\
\hline HQ1 & $0 ; 1$ & $\mathrm{R}$ & $0 ; 1$ & $\mathrm{R}$ & 0 & $\mathrm{R}$ \\
\hline HQ9 & 3 & $\mathrm{~S}$ & 3 & $\mathrm{~S}$ & $3-$ & $\mathrm{S}$ \\
\hline HQ18 & $0 ; 1$ & $\mathrm{R}$ & $0 ; 1$ & $\mathrm{R}$ & 0 & $\mathrm{R}$ \\
\hline MDQ27 & 3 & $\mathrm{~S}$ & $3+$ & $\mathrm{S}$ & $3-$ & $\mathrm{S}$ \\
\hline MDQ28 & 21 & MR & 0 & $\mathrm{R}$ & 0 & $\mathrm{R}$ \\
\hline MDQ29 & 12 & $\mathrm{R}$ & $0 ; 1$ & $\mathrm{R}$ & 0 & $\mathrm{R}$ \\
\hline SQ31 & 3 & $\mathrm{~S}$ & 3 & $\mathrm{~S}$ & 0 & $\mathrm{R}$ \\
\hline SQ36 & 3 & $\mathrm{~S}$ & $3-$ & MS & $23-$ & MR \\
\hline SQ41 & 3 & $\mathrm{~S}$ & 3 & S & 0 & $\mathrm{R}$ \\
\hline SQ44 & 1 & $\mathrm{R}$ & NA & NA & NA & NA \\
\hline SQ46 & 21 & MR & NA & NA & NA & NA \\
\hline SQ47 & $0 ; 1$ & $\mathrm{R}$ & $3-$ & $\mathrm{S}$ & 0 & $\mathrm{R}$ \\
\hline SQ48 & 21 & MR & 3 & $\mathrm{~S}$ & 0 & $\mathrm{R}$ \\
\hline SQ55 & 3 & $\mathrm{~S}$ & 3 & $\mathrm{~S}$ & $0 ; 1$ & $\mathrm{R}$ \\
\hline Q21861 & $0 ; 1$ & $\mathrm{R}$ & $0 ; 1$ & $\mathrm{R}$ & 0 & $\mathrm{R}$ \\
\hline Harrington & 3 & $\mathrm{~S}$ & 3 & $\mathrm{~S}$ & 3 & S \\
\hline MD2 & 3 & $\mathrm{~S}$ & 3 & $\mathrm{~S}$ & 3 & $\mathrm{~S}$ \\
\hline Steptoe & 3 & $\mathrm{~S}$ & 3 & $\mathrm{~S}$ & 3 & $\mathrm{~S}$ \\
\hline SM89010 & 3 & $\mathrm{~S}$ & 3 & $\mathrm{~S}$ & 3 & $\mathrm{~S}$ \\
\hline Q asRpg5 & 32 & $\mathrm{~S}$ & NA & NA & NA & NA \\
\hline Q asHvRga1 & 23 & $\mathrm{~S}$ & NA & NA & NA & NA \\
\hline Q asHvAdf3 & 23 & $\mathrm{~S}$ & NA & NA & NA & NA \\
\hline $\mathrm{QpBs}$ & $0 ; 1$ & $\mathrm{R}$ & NA & NA & NA & NA \\
\hline
\end{tabular}

${ }^{a}$ IT-M is the mode IT observed based on the 0-to-4 scale of Stakeman et al. (1962). GR is the general reaction: R (resistant), MR (moderately resistant), MS (moderately susceptible), S (susceptible), and NA (data not available).

\begin{tabular}{|c|c|c|c|c|c|c|}
\hline RPG5 & & 5 'region & NBS 522 & LRR & 1050 & STPK \\
\hline Q21861 & (R) & 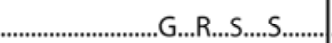 & ........... & & & \\
\hline MD2 & (S) & $\ldots$ & & & & \\
\hline Harrington & (S) & $\ldots$ & ........... & $80 \%$ aa identity & 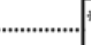 & \\
\hline $\begin{array}{l}\text { Morex } \\
\text { Steptoe }\end{array}$ & $\begin{array}{l}\text { (S) } \\
\text { (S) }\end{array}$ & $\ldots+.^{*}$ & & & & $\mathrm{PP} 2 \mathrm{C}$ \\
\hline
\end{tabular}

\begin{tabular}{|c|c|c|c|c|c|c|}
\hline \multicolumn{2}{|c|}{ HvRGA1 } & NBS & LRR & HvADF3 & & \\
\hline Q21861 & (R) & ..................... & .....M..................... & Q21861 & (R) & \\
\hline MD2 & (S) & 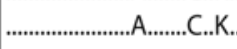 & A...M ..................... & MD2 & (S) & \\
\hline Harrington & (S) & 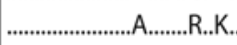 & A...M & Harrington & (S) & \\
\hline Morex & (S) & 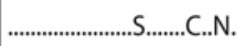 & 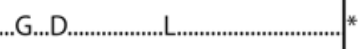 & Morex & (S) & $100 \%$ aa identity \\
\hline Steptoe & (S) & 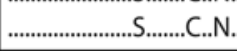 & ...G...D.................................................. & Steptoe & (S) & \\
\hline
\end{tabular}

Fig. 3. Protein domain structures and allele analyses for Rpg5, $H v$ Rga1, and $H v$ Adf3 genes. Boxes represent the different protein domains, with the boundaries shown above as amino acid positions. Barley lines used in the allele analysis are labeled to the left, with general reaction to stem rust isolates and races shown as R (resistant) or S (susceptible). Differences in amino acid sequence compared with the 'Q21861' resistance allele are indicated by single aminoacid (aa) letter designations, with the relative positions of the polymorphisms shown by amino-acid numbering defining the boxes representing the protein domains. The leucine-rich repeat region of the Rpg5 alleles of 'Harrington' and Q21861 are diverged and shown as 80\% amino-acid identity. The HvAdf3 gene is shown as $100 \%$ amino acid identity for the lines analyzed. 
teins, have very little sequence homology, with conservation present only among very short regions of the NBS conserved domains.

Sequence comparison between the Q21861 resistant and MD2 susceptible $H v$ Rgal alleles showed $100 \%$ identity at the amino acid level (Fig. 3). Expression analysis using reversetranscriptase polymerase chain reaction (RT-PCR) indicated that the alleles were expressed from both Q21861 and MD2 at similar levels (data not presented). The susceptible Harrington contained an allele that differed from Q21861 by only a single amino acid (C324R). The susceptible Morex and Steptoe share an identical amino acid sequence, different from the Q21861 allele by 5 aa: S290A, K340N, A445G, M474D, and F586L (Fig. 3).

HvAdf3 is predicted to encode a small, 144-aa (approximately $15.8 \mathrm{kDa}$ ) protein that contains the domains indicative of a functional actin depolymerizing-like protein. The HvAdf3 gene is highly conserved, with $100 \%$ amino acid similarity between the resistant and susceptible barley cultivars examined (Fig. 3) (Brueggeman et al. 2008). Expression quantitative trait locus (eQTL) analysis of the $H v$ Adf 3 transcript levels using the Affymetrix Barley1 Gene Chip suggested that the gene is differentially expressed between the susceptible line SM89010 and the resistant line Q21861 at $24 \mathrm{~h}$ postinoculation with $P$. graminis f. sp. tritici race TTKSK (Moscou et al. 2011). However, we are currently conducting a thorough analysis of $H v$ Adf 3 expression across several time points post $P$. graminis f. sp. tritici race QCCJ inoculation in resistant and susceptible barley lines using quantitative polymerase chain reaction (QPCR) assays.

\section{VIGS of genes at the Rpg5 locus.}

To determine which candidate gene or genes at RMRL1 are required for resistance against races QCCJ and TTKSK, the BSMV-mediated VIGS system was used to post-transcriptionally silence each gene in barley line Q21861. Following VIGS, the seedlings were inoculated with $P$. graminis $\mathrm{f}$. sp. tritici race QCCJ. The BSMV-VIGS constructs were developed containing 253, 275, and 291 bp of antisense cDNA from the $H v$ Rgal, HvAdf3, and Rpg5 genes, respectively (Fig. 4A and B). The BSMV-VIGS-infected plants were inoculated with $P$. graminis f. sp. tritici race QCCJ and, after a 14- to 17-day incubation
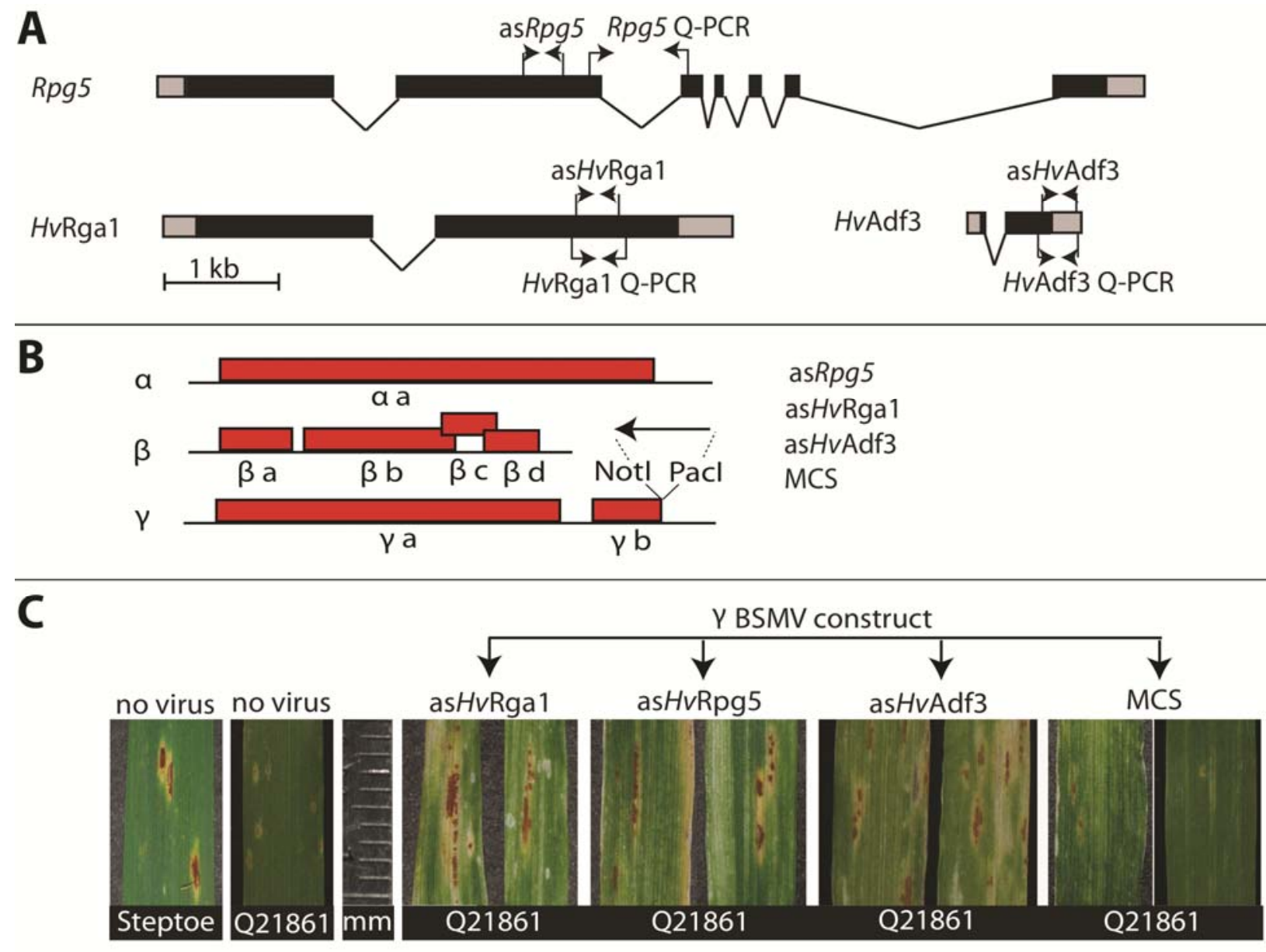

Puccinia graminis f. sp. tritici race QCCJ

Fig. 4. Barley stripe mosaic virus (BSMV) virus-induced gene silencing (VIGS) of candidate genes required for race QCCJ resistance. A, Gene structures of Rpg5, HvRga1, and HvAdf3. Black bars represent the exons and intervening thin lines represent the introns. Arrows represent the position of primer pairs used to design BSMV-VIGS antisense constructs (asRpg5, as $H v$ Rga1, and as $H v$ Adf3) and primers used for quantitative polymerase chain reaction (Q-PCR) analysis (Rpg5-Q-PCR, $H v$ Rga1-Q-PCR, and $H v$ Adf3-Q-PCR). B, BSMV tripartite genome showing $\alpha$, $\beta$, and $\gamma$ genomes, with the arrow representing the antisense insertions for the asRpg5, asHvRga1, asHvAdf3, and MCS antisense constructs. The BSMV-MCS control is a BSMV-VIGSplasmid previously shown not to have homologous sequences in the barley genome. C, VIGS of the Rpg5, HvRga1, and HvAdf3 genes in Puccinia graminis f. sp. tritici race QCCJ resistant barley line 'Q21861' results in a shift from incompatibility to compatibility with P. graminis f. sp. tritici race QCCJ. Barley seedlings were inoculated with Rpg5, HvRga1, and HvAdf3 antisense (as) or pBluescript MCS control BSMV-VIGS constructs. 'Steptoe' and Q21861 are susceptible and resistant virus mock-inoculated controls, respectively. All BSMV-VIGS experiments were done in the Q21861 resistant line. The scale in millimeters is shown in the lane labeled "mm". 
period, rust infection types (IT) were classed as either compatible or incompatible. As controls, we included virus-inoculated controls (BSMV-MCS) and mock-inoculated Q21861. The BSMV-MCS control is a BSMV-VIGS construct containing a fragment of the pBluescript K/S plasmid (Stratagene, La Jolla, CA, U.S.A.), previously shown not to have homologous sequences in the barley genome (Brueggeman et al. 2008). The IT varied on the plants inoculated with gene-specific BSMV constructs, ranging from resistant to susceptible, but we did not observe plants with a susceptible IT on the BSMV-MCS virus-inoculated controls or mock-inoculated controls. The resistant IT observed on the asRpg5-, asHvRga1-, and as $H v$ Adf3-silenced plants were most probably the result of silencing variability, commonly observed between plants in VIGS experiments. Individual BSMV-asRpg5 plants tested by Q-PCR showed 0 to $79 \%$ silencing of Rpg 5 compared with the virus mock-inoculated controls. This result indicated that the silencing among plants in our experiments also had high variability even when virus symptoms and severity were similar. Infection of Q21861 with the BSMV-asHvRga1, BSMV-asRpg5, BSMV-as $H v$ Adf3, or BSMV-MCS constructs produced similar BSMV symptoms, including stunted plants with distorted, mottled, and striped leaves, indicating systemic BSMV infection. No such symptoms were observed in the mock-inoculated plants. After inoculation with $P$. graminis f. sp. tritici race QCCJ, there was no indication of the rust-specific compatible interaction in Q21861 plants preinoculated with BSMV-MCS; however, silencing of any of the three candidate genes using BSMV-asHvRga1, BSMV-asRpg5, and BSMV-asHvAdf3 constructs followed by inoculation with $P$. graminis $\mathrm{f}$. $\mathrm{sp}$. tritici race QCCJ resulted in development of clearly compatible rust-specific symptoms in Q21861 and, as expected, in Steptoe, the QCCJ-susceptible control. The compatible symptoms were not observed in the BSMV-MCS-inoculated controls and mock-inoculated controls (Fig. 4C). It must be noted that the BSMV-asHvRga1, BSMV-asRpg5, and BSMVas $H v$ Adf3 plants exhibited mesothetic reactions typical in barley of 1 to $3+$, based on a modified 0-to-4 scale of Stakman and associates (1962) (Sun and Steffenson 2005). However, the susceptible IT (or compatible reactions) of $3-$ to $3+$, characterized by the development of large, 2- to 4-mm pustules surrounded by chlorosis, were not observed on BSMVMCS virus-inoculated controls or the virus mock-inoculated Q21861 plants. The BSMV-MCS virus-inoculated and mockinoculated controls consistently exhibited small $(<1 \mathrm{~mm})$ pustules surrounded by small chlorotic or necrotic regions defining an incompatible stem rust interaction (Fig. 4C; Table 1). Many of the stem rust pustules that developed within the chlorotic stripes of the BSMV-asRpg5-, BSMV-asHvRga1, and BSMV-as $H v$ Adf3-infected plants were elongated, following the stripe patterns of the virus infection (Fig. 4C). These elongated pustules were scored as compatible interactions (IT 3+). The BSMV-MCS-inoculated Q21861 seedling controls exhibited only incompatible stem rust IT, even in the regions of the leaf with severe virus symptoms.

\section{Transcript analysis.}

The Q-PCR analysis determined that the BSMV-asRpg5-, BSMV-asHvRga1-, and BSMV-asHvAdf3-inoculated plants had significantly reduced levels of the corresponding mRNA transcript, averaging 60, 39, and 54\% decrease in relative expression, respectively, as compared with the BSMV-MCS virusinoculated controls (Table 2). The BSMV-MCS controls were subjected to the same regimen of treatments as the genespecific constructs, with the only differences being the absence of the gene-specific antisense sequence. The gene-specific BSMV constructs showed no significant effect on the relative expression levels of the genes not targeted for silencing, demonstrating that the virus infection with the constructs used in these experiments had no effect on the expression of the other genes at RMRL1 (Table 2). Analysis using available barley sequencing data, National Center for Biotechnology Information (NCBI) nonredundant nucleotide database; NCBI expressed sequence tag (EST) (Hordeum) and HarvEST; Barley 1.83 Assembly 36 determined that the LRR regions which were targeted by the VIGS constructs for the Rpg5 and $H v$ Rgal genes identified one gene family member for Rpg 5 with $73 \%$ sequence homology (GenBank accession number AK370199.1) and no closely related genes were identified in barley with the $H v$ Rga 1 sequence. These data were supported by BAC hybridization experiments and both Southern and Northern blot analysis. An $H \nu$ Rga1 NBS-LRR-specific probe was hybridized to Southern blots producing a single band (Supplementary Fig. S1), suggesting that it does not belong to a gene family. An Rpg5 NBS-LRR-specific probe was also hybridized to Northern and Southern blots, also producing single bands. Additionally, BAC hybridization analysis revealed that Rpg 5 belongs to a gene family containing two genes, Rpg5 and a closely related gene encoding an STPK. The STPK gene with high homology to the RPG5 protein kinase (89\% nucleic acid identity) does not appear to be connected to an NBS-LRR region with homology to the Rpg5 LRR domain that was targeted for silencing (Fig. 4). These data suggest that the BSMV-VIGS constructs should be specifically silencing Rpg5 and $H v$ Rgal.

Analysis using available barley sequencing data and Southern analysis determined that $H v$ Adf 3 is a member of a family of Adf genes, which includes the three Adf genes (HvAdf1, $H v$ Adf2, and $H v$ Adf 3 ) present at RMRL. The HvAdf2 is the most closely related to $H v$ Adf3 ( $86 \%$ nucleic acid homology) and $H v$ Adf1 has $80 \%$ homology to $H v$ Adf 2 but is diverged from $H v A d f 3$, with BLASTn analysis showing no significant similarity between $H v$ Adf1 and $H v$ Adf3. We designed the BSMV-as $H v$ Adf 3 construct to target the $3^{\prime}$ untranslated region, a region of $H v$ Adf 3 that is completely diverged from $H v$ Adf 2 and $H v$ Adf 1 ; thus, we are confident that the BSMV-VIGS construct is specifically silencing only the targeted gene.

Table 2. Quantitative polymerase chain reaction analysis of Rpg5, HvRga1, and $H v$ Adf3 gene expression after silencing by Barley stripe mosaic virus (BSMV) virus-induced gene silencing (VIGS) shown as relative expression levels compared with the BSMV-MCS virus-inoculated control

\begin{tabular}{|c|c|c|c|c|c|c|c|c|c|}
\hline \multirow[b]{3}{*}{ Gene } & \multicolumn{9}{|c|}{ BSMV construct ${ }^{\mathrm{a}}$} \\
\hline & \multicolumn{3}{|c|}{ asRpg 5} & \multicolumn{3}{|c|}{ asHvRga1 } & \multicolumn{3}{|c|}{ asHvAdf3 } \\
\hline & $\mathbf{R E}$ & SD & $\operatorname{MED}(\%)$ & $\mathbf{R E}$ & SD & $\operatorname{MED}(\%)$ & $\mathbf{R E}$ & SD & $\operatorname{MED}(\%)$ \\
\hline$R p g$ & $40^{*}$ & 7 & -60 & 100 & 18 & 0 & 98 & 37 & -2 \\
\hline$H \nu \operatorname{Rga} 1$ & 104 & 25 & 4 & $61 *$ & 43 & -39 & 116 & 3 & 16 \\
\hline HvAdf3 & 122 & 19 & 22 & 105 & 29 & 5 & $46^{*}$ & 17 & -54 \\
\hline
\end{tabular}

${ }^{a}$ Relative expression (RE) levels are a percentage of the BSMV-MCS virus control expression levels normalized against the barley ubiquitin gene. Standard deviation (SD) was calculated from values obtained from three biological replicates. Mean expression difference (MED) is in comparison to the expression levels in the BSMV-MCS controls. An asterisk (*) indicates that values are significantly different at $\alpha=0.01$ using $\chi^{2}$ analysis. 


\section{DISCUSSION}

Research of stem rust resistance genes in barley has resulted in the cloning and partial characterization of Rpgl from Morex (Brueggeman et al. 2002; Kleinhofs et al. 2009) and Rpg5 from barley line Q21861 (Brueggeman et al. 2008). We previously reported a genetically defined interval delimiting a small physical region of approximately $1 \mathrm{kbp}$ containing only a single gene $(H v$ Adf 2$)$ believed to be the candidate rpg4 gene (Brueggeman et al. 2008, 2009). The HvAdf2 gene was identified by virtue of somewhat ambiguous recombinant analysis that either included or eliminated resistance to $P$. graminis $\mathrm{f} . \mathrm{sp}$. tritici race QCCJ (Brueggeman et al. 2008). However, using backcrossing experiments described in this article, we eliminated $H v$ Adf 2 as an $r p g 4$ candidate gene and, more importantly, identified two distinct yet tightly linked loci that are required for rpg4-mediated resistance against $P$. graminis f. sp. tritici races QCCJ and TTKSK. The first region (RMRL2) is up to $220 \mathrm{kbp}$ distal to the HvAdf2 gene, and was detected only in the SQ population. The second region (RMRL1), detected in the HQ and MD2Q populations, lies up to $70 \mathrm{kbp}$ proximal to HvAdf2 gene (Figs. 1 and 2). These genetic data eliminating $H v$ Adf 2 as the candidate rpg4 gene also were confirmed by BSMV-VIGS analysis, showing that silencing of the HvAdf2 gene had no effect on the $P$. graminis $\mathrm{f}$. sp. tritici race QCCJ incompatible IT on line Q21861 (Chai 2011).

The genetic analysis indicated that RMRL2, located distal of the Rsnp.2 marker, only segregated for resistance in the SQ population. This suggests that the gene required for rpg4-mediated resistance at RMRL2, designated Rme1, is a functional allele from Q21861 and nonfunctional from Steptoe. The resistant HQ and MD2Q recombinant lines HQ1, HQ18, MD2Q28, and MD2Q29 contain the Q21861 genotype at RMRL1 and susceptible genotype at RMRL2, suggesting that Harrington and MD2 are susceptible due to a nonfunctional gene at RMRL1 but contain functional Rmel alleles that cooperate with the genes at RMRL1 to provide resistance against $P$. graminis f. sp. tritici races QCCJ and TTKSK. The $P$. graminis f. sp. tritici-susceptible parent Harrington does not contain a functional Rpg5 allele (Fig. 3), and the resistant HQ18 recombinant combines susceptible Harrington genotype from Rsnp.2, including HvAdf2, and distal, with the Q21861 genotype at RMRL1, indicating that Harrington is susceptible due to the lack of a functional gene at RMRL1 (Fig. 1).

The smallest RMRL1 interval required for race QCCJ resistance, defined by the HQ recombinant lines HQ18 and HQ9, contains three candidate genes: HvRga1, Rpg5, and HvAdf3 (Figs. 1 and 2). The Rpg5 gene was considered the most likely candidate gene required for resistance to $P$. graminis $\mathrm{f}$. $\mathrm{sp}$. tritici races QCCJ and TTKSK at RMRL1 because it confers resistance to rye stem rust isolate 92-MN-90 (Brueggeman et al. 2008). Analysis of Rpg5 alleles from multiple barley lines resistant and susceptible to $P$. graminis f. sp. tritici races QCCJ and TTKSK showed that a predicted functional allele corresponded perfectly with resistance (data not presented). The other two genes in the region, $H v$ Rgal and $H v A d f 3$, were not considered to be good candidates required for rpg4-mediated resistance because allele sequences were highly conserved among cultivars resistant and susceptible to $P$. graminis f. sp. tritici races QCCJ and TTKSK with respect to amino acid identity. Resistant and susceptible $H v$ Rgal alleles were $100 \%$ identical or had a few minor amino acid substitutions and all HvAdf3resistant and -susceptible alleles had $100 \%$ amino acid conservation (Fig. 3) (Brueggeman et al. 2008). However, all three genes present at the locus contained protein domains implicated in defense responses and could have differential transcription regulation. Because no recombinant lines were iden- tified separating these genes in a population representing 5,232 recombination events, the function of each gene was examined independently using post-transcriptional gene silencing.

The BSMV-VIGS system is an important tool that can be utilized to test the function of genes by post-transcriptional gene silencing in barley and wheat (Hein et al. 2005; Holzberg et al. 2002; Scofield et al. 2005). We utilized VIGS to silence each gene at RMRL1 to determine which genes are required for rpg4-mediated resistance against $P$. graminis f. sp. tritici race QCCJ. Based on IT assays with $P$. graminis f. sp. tritici race QCCJ and the corresponding Q-PCR data, it was unexpectedly determined that $R p g 5, H v$ Rga1, and $H v$ Adf 3 are all required for rpg4-mediated resistance. These data determined that rpg4-mediated resistance is not determined by a single gene but requires concerted interaction of three genes at RMRL1 and at least one additional gene at RMRL2 (Fig. 2).

The Rpg5 gene is a unique disease resistance gene containing the R protein domains NBS-LRR and STPK, typically present in two separate proteins representing two of the major classes of $R$ genes (Brueggeman et al. 2008). However, the recent cloning of the wheat tan spot susceptibility gene $T s n 1$ has revealed a dominant STPK-NBS-LRR susceptibility factor which may act in a reverse gene-for-gene interaction with the necrotrophic fungal pathogen Stagonospora nodorum (Faris et al. 2010). The $H v$ Rgal gene, located approximately $20 \mathrm{kbp}$ distal of Rpg5 with inverted gene orientation, is predicted to encode a typical NBS-LRR domain R protein (Figs. 2C and 3B). Silencing of either Rpg5 or $H v$ Rgal resulted in similar compatible (susceptible) phenotypes (Fig. 4C; Table 1), indicating that neither the Rpg5 nor $H v$ Rgal NBS-LRR domain containing $R$ genes alone are capable of eliciting the resistance reaction. Thus, it appears that both genes are required together for $r p g$ 4-mediated resistance against $P$. graminis f. sp. tritici race QCCJ. This research demonstrates that resistance to stem rust race QCCJ, presumed to harbor a specific rpg4-AVR gene, requires two unrelated NBS-LRR domain genes for pathogen recognition or to elicit the race-specific resistance response. Recent data have suggested that some NBS-LRR genes are modular and that the discrete modules or protein fragments are sufficient to initiate defense signaling (Eitas and Dangl 2010). This suggests that NBS-LRR proteins that act coincident in defense complexes may interact in different combinations of domain structure to recognize unique effector molecules or to trigger different resistance pathways. The RPG5 and $H v$ RGA1 proteins may interact forming heterodimers, with both proteins required for the recognition of the wheat stem rust $a v r$ genes encoded by $P$. graminis f. sp. tritici races QCCJ and TTKSK. However, the possibility exists that one of the two NBS-LRR domain-containing genes functions downstream of the other, possibly guarding a virulence target, or is involved in downstream signaling.

The predicted RPG5 protein contains an STPK domain, implicating its involvement in a signaling pathway that may be activated upon $R p g 5 / H v$ Rgal pathogen recognition. The recognition may trigger phosphorylation of the STPK domain and provide the initial step in a phosphorylation-signaling cascade, resulting in the resistance response. Recent research has shown that the RPG1 stem rust resistance protein, containing a functional STPK domain similar to but not closely related to the Rpg5 STPK, undergoes a rapid phosphorylation in response to incompatible $P$. graminis f. sp. tritici races. The phosphorylation is specific to the resistance response, suggesting that it may be the initial signaling event in the stem rust resistance mechanism (Nirmala et al. 2010). Alternatively, the STPK domain may act as an effector target that is guarded by the NBSLRR protein domains. Studies with RIN4, PBS1, and Pto show that NBS-LRR guard proteins may constitutively bind to the 
effector targets, which are STPK proteins in the case of PBS1 and Pto. In the Rpg5 system, it is possible that the NBS-LRR guard and STPK guardee are encoded by a single gene and present in a single protein.

The HvAdf3 requirement for resistance was surprising because it was originally presumed that Rpg5 would be the gene at the locus required for resistance. Four genes, including the gene present at RMRL2, required for resistance may raise concerns about the specificity of our silencing experiments. However, after three replications of the VIGS experiments with the three gene-specific constructs and the control virus, the results were consistently reproduced, determining that the specific silencing of each gene had an effect in converting incompatible to compatible reactions between the pathogen, $P$. graminis f. sp. tritici race QCCJ, and the normally resistant barley line Q21861. Recent research has determined that BSMV infection affects susceptibility to fungal pathogens in wheat and perhaps barley as well (Tufan et al. 2011). Our experiments were performed with a proper BSMV-VIGS control vector (BSMVMCS), which did not show any affect on the incompatible interactions between $P$. graminis f. sp. tritici race QCCJ and the resistant line Q21861. All of our silencing comparisons were also made as a percentage of gene expression compared with the BSMV-MCS control, and it was shown that the gene-specific constructs were specifically silencing the targeted gene. Thus, we are confident that the shift from resistance to susceptibility was a specific response to the silencing of the targeted genes and not due to the BSMV infection.

The requirement of the actin depolymerizing factor for resistance is intriguing and we would like to determine whether the HvAdf3 gene is required for this specific resistance reaction or if it is required for many different resistance pathways and is a component of nonrace-specific resistance. Experiments are underway to test the specificity of the HvAdf3-silencing response to other stem rust races and pathogen species. Tian and associates (2009) have shown that the Arabidopsis AtAdf4 gene is required for the $R P S 5 / P B S 1$ resistance reaction against Pseudomonas syringae harboring AvrPphB, setting precedence for the requirement of NBS-LRR, STPK, and ADF protein domains together for race-specific resistance against a pathogen harboring a specific AVR protein. Interestingly, the Arabidopsis RPS5 NBS-LRR domain (GenBank accession number AEE28851.1) shares 23\% amino acid identity and 40\% similarity with the RPG5 NBS-LRR domain (GenBank accession number ACG68417.1) and no significant similarity with the NBS-LRR domain of $H v$ Rgal (GenBank accession number EU878778.1). The PBS1 STPK (accession number AED91858.1) also shows $53 \%$ amino acid identity and $66 \%$ similarity to the RPG5 STPK (accession number ACG68417.1). The actin depolymerizing factor-like gene, $H v$ Adf 3 , shown to be required for resistance in this study, also has $52 \%$ amino acid identity and $76 \%$ similarity with AtAdf4 (AT5G59890). We suspect that the $\mathrm{Rpg} 5 / \mathrm{Hv} \mathrm{Rga} / \mathrm{Hv} \mathrm{Adf} 3$-mediated stem rust resistance in barley may be functionally similar to the RPS5/PBS1/ AtADF4-mediated $P$. syringae resistance in Arabidopsis and are utilizing the Arabidopsis model for future functional analysis research on stem rust resistance in barley.

A recent study using eQTL analysis of a SM89010/Q21861 double haploid population indicated that the SM89010-susceptible allele of the $H v$ Adf 3 gene is upregulated and the differential regulation is in response to infection by race TTKSK (Moscou et al. 2011). The data presented from the eQTL study suggested that upregulation of $H v A d f 3$ may determine susceptibility and HvAdf3 may function as a dominant susceptibility factor that potentially determines the recessive nature of rpg4-mediated resistance. The results presented here are contradictory to the hypothesis put forth by Moscou and associates (2011) because we determined that silencing of $H v$ Adf3 resulted in a shift from resistance to susceptibility in line Q21861. This result suggests that the ADF protein is required for resistance similar to that reported for the RPS5/ AtADF4 resistance mechanism in Arabidopsis against $P$. syringae (Tian et al. 2009).

We have demonstrated that a complex genetic system consisting of at least four genes at two tightly linked loci interact to confer rpg4-mediated Puccinia graminis f. sp. tritici race QCCJ resistance. The high-resolution mapping determined that resistance to $P$. graminis $\mathrm{f}$. $\mathrm{sp}$. tritici race TTKSK, previously mapped to the region in a low-resolution population (Steffenson et al. 2009), maps to the same tightly linked genetic intervals, RMRL1 and RMRL2, identified with $P$. graminis $\mathrm{f}$. sp. tritici race QCCJ, indicating that the same host resistance genes in the three populations analyzed provide resistance to both pathogen races. This research characterizing RMRL1 and RMRL2 was performed using $P$. graminis $\mathrm{f}$. sp. tritici race QCCJ because of the limitations on the use of race TTKSK. However, it is still important to individually test the requirement of the Rpg5, HvRga1, and HvAdf3 genes in race TTKSK resistance, and this research is underway.

The identification and validation of the rpg4 gene has eluded our efforts but now we are beginning to unravel its complexities. The new information presented here begins to define the RMRL and will be utilized to identify and validate the remaining Rmel gene that is still unknown. We delimited the RMRL2 locus and generated a low pass sequence of the approximately $220 \mathrm{~kb}$ region. Three candidate Rmel genes have been identified, including a heat shock protein 70 $(H v H s p 70)$, a zinc finger SEC14 protein (HvZF-SEC14), and a third actin depolymerization like protein ( $H v$ Adf 1$)$. We are currently generating a complete sequence of the region by ion torrent sequencing technology, and validation of the candidate genes is underway.

Recent research on stem rust resistance in barley has raised many questions but the ones we are most interested in answering are why rpg4-mediated resistance is recessive and temperature sensitive and whether the resistance is an early response or prehaustorial form of resistance, similar to what is expected in a nonhost-resistance mechanism. We have strong genetic evidence showing that the recessive nature of rpg4-mediated resistance against the wheat stem rust pathogens is determined by the presence of an $H v$ PP2C gene in place of the STPK domain of the majority of the $P$. graminis f. sp. tritici race QCCJand TTKSK-susceptible barley lines. Crosses between Q21861 and these susceptible genotypes resulted in susceptible $F_{1}$ progeny whereas crosses between Q21861 and susceptible genotypes containing a nonfunctional rpg5 allele with the $H \nu \mathrm{PP} 2 \mathrm{C}$ gene absent results in resistant $\mathrm{F}_{1}$ progeny (data not shown). Thus, the Rpg5 gene in the absence of the HvPP2C protein and presence of a functional Rmel allele appears to behave as a dominant $R$ gene mediating wheat stem rust resistance, otherwise considered rpg4-mediated resistance. The genetic data suggest that the $H \nu \mathrm{PP} 2 \mathrm{C}$ may act as a dominant susceptibility factor, and a possible hypothesis is that PP2C activity suppresses the resistance response mediated by the RPG5 protein kinase similar to the Rice Xa21 protein-kinasemediated resistance being suppressed by the XB15 protein phosphatase 2C gene (Park et al. 2008). Further research and validation of the $H v \mathrm{PP} 2 \mathrm{C}$ gene is required to elucidate this complex genetic interaction; however, this research may answer the question of rpg4-mediated recessive resistance. Perhaps the other questions will also be answered once the remaining Rmel gene required for wheat stem rust resistance is characterized and the temporal and spatial occurrence of the host-pathogen interactions are elucidated. 


\section{MATERIALS AND METHODS}

\section{Genetic and physical mapping.}

The high-resolution genetic map of RMRL was constructed from the progeny of the crosses Steptoe $\times$ Q21861, Harrington $\times$ Q21861, and MD2 $\times$ Q21861, as described by Brueggeman and associates (2008). Fourteen lines were identified with recombinations occurring between the SNP marker Rsnp.4 and RFLP marker ARD5112. In this study, these 14 recombinants were genotyped at RMRL using SNP and simple-sequence repeat markers (Figs. 1 and 2) developed utilizing a sequence generated from the Morex BAC contig spanning the rpg4l Rpg5 region (Brueggeman et al. 2008) (GenBank accession number EU812563).

\section{Molecular markers.}

The SNP and STS markers were developed using predicted genes or low-copy regions identified from the Morex BAC sequences as described by Druka and associates (2000). The alleles were sequenced from the parental lines. Amplifications were performed in a Mastercycler Pro programmable thermocycler (Eppendorf, Hauppauge, NY, U.S.A.) at $95^{\circ} \mathrm{C}$ for $4 \mathrm{~min}$; followed by 35 cycles of $95^{\circ} \mathrm{C}$ for $30 \mathrm{~s}, 62^{\circ} \mathrm{C}$ for 1 min, and $72^{\circ} \mathrm{C}$ for $1 \mathrm{~min}$; followed by $72^{\circ} \mathrm{C}$ for $5 \mathrm{~min}$. The PCR amplification reactions contained approximately $100 \mathrm{ng}$ of genomic DNA, $0.2 \mathrm{mM}$ dNTP mix, 30 pmol of each forward and reverse gene-specific primer, $1.5 \mu \mathrm{l}$ of RedTaq DNA polymerase (Sigma-Aldrich, St. Louis), and $3 \mu \mathrm{l}$ of $10 \times$ RedTaq reaction buffer in a $30-\mu l$ volume. The physical locations of the primers used for each marker are relative to the Morex BAC sequence or Q21861 genomic sequence from the RMRL (GenBank accession number EU812563 or EU878778, respectively) or the low-copy HindIII subclone sequences from BAC $64 \mathrm{H} 24$.

\section{Disease phenotyping.}

The recombinant lines and the parents were inoculated with $P$. graminis $\mathrm{f}$. sp. tritici race QCCJ according to previously established methods (Steffenson et al. 2009). IT were assessed 12 to 14 days postinoculation using a 0 -to- 4 scale modified from the one developed for wheat by Stakman and associates (1962) (Sun and Steffenson 2005). The IT data were simplified in Table 1 to show the most common IT (i.e., the IT mode) and the general reaction. Classification of recombinant lines into resistant and susceptible categories was based on the reaction of the parents to $P$. graminis f. sp. tritici races QCCJ and TTKSK and $P$. graminis $\mathrm{f}$. sp. secalis isolate 92MN-90. The recombinant lines were analyzed several times with $P$. graminis f. sp. tritici race QCCJ at the University of Minnesota and North Dakota State University (Table 1). Plants were grown and assayed for their disease reaction as previously described (Brueggeman et al. 2008). IT analysis using $P$. graminis f. sp. tritici race TTKSK at the seedling stage was performed in the Biosecurity level-3 (BSL-3) facility in St Paul, MN (U.S.A.).

\section{BSMV VIGS.}

BSMV-VIGS constructs were developed using the BSMV $\gamma$ RNA-based vector previously described by Hein and associates (2005). Construction of the HvRga1, Rpg5, and HvAdf3 gene-specific constructs was performed by amplifying 253- to 291-bp cDNA fragments from the HvRga1, HvAdf3, and Rpg 5 cDNAs (GenBank accession number EU878778) using genespecific primers with five prime terminal NotI or PacI adaptor sequences. Constructs, plant growth, and infection protocols were performed as described in Brueggeman and associates (2008).

\section{Real-time Q-PCR.}

Tissue samples were taken from the different virus-infected plants and controls at the time of fungal inoculation 14 to 17 days post virus inoculation. The three biological replicates were bulks of three random, gene-specific, BSMV-infected plants; virus-inoculated BSMV-MCS control plants; or mock-inoculated control plants. Total RNA was extracted using a modified Trizol extraction method as described by Brueggeman and associates (2008). To generate first-strand cDNA, $1 \mu \mathrm{g}$ of total RNA was annealed with $2 \mu \mathrm{m}$ oligo-dT primer in a $20-\mu \mathrm{l}$ reaction and converted to single-stranded cDNA using the Reverse Transcription System (Promega Corp., Madison, WI, U.S.A.) following the manufacturer's recommended procedure. The 20$\mu 1$ RT-PCR reactions were diluted with $40 \mu \mathrm{l}$ of $\mathrm{H}_{2} \mathrm{O}$ to $60 \mu \mathrm{l}$, and 5- $\mu \mathrm{l}$ aliquots of the diluted cDNA template were used as template for amplification with gene-specific primers using iQ SYBR Green Supermix (Bio-Rad, Hercules, CA, U.S.A.) in $25-\mu l$ reactions following the manufacturer's standard procedure. Primer sequences for Rpg5, $H v \mathrm{Adf} 3$, and $H v$ Rgal were designed to specifically amplify 193-, 355-, and 372-bp fragments of cDNA, respectively. The Q-PCR amplicons were outside the regions targeted by the BSMV constructs to avoid amplification from the virus-encoded antisense cDNA fragments. The barley Ubil gene primer sequences are described by Rostoks and associates (2003). Q-PCR was performed in a CFX96 Real-Time System thermocycler (Bio-Rad) using the following parameters: $2 \mathrm{~min}$ at $50^{\circ} \mathrm{C}$ and hot start for $15 \mathrm{~min}$ at $95^{\circ} \mathrm{C}$, followed by 40 cycles, each consisting of $15 \mathrm{~s}$ of denaturing at $95^{\circ} \mathrm{C}, 20 \mathrm{~s}$ of annealing at $60^{\circ} \mathrm{C}, 30 \mathrm{~s}$ of primer extension at $72^{\circ} \mathrm{C}$, and $15 \mathrm{~s}$ of data acquisition at a temperature specific for each PCR fragment. Quantification of the targeted gene mRNA transcript (Rpg5, HvRgal, and HvAdf3) and the reference gene (Ubil) was determined using standard curves generated using external cDNA standards covering eight magnitudes (10 pg down to $1 \mathrm{ag}$ ). Three experimental replicates of Q-PCR experiments were performed and expression levels were normalized to the mean expression level of ubiquitin for each biological replicate. Normalized percent values of the three biological replicates for each construct were used to calculate the average expression level of the VIGS-targeted genes and standard deviations. The values for Table 2 are given as expression levels as a percent of the BSMV-MCS virus-inoculated control. A $\chi^{2}$ test was used to compare expression levels, with significance assessed at $\alpha=0.01$.

\section{ACKNOWLEDGMENTS}

This project was supported by the National Research Initiative Competitive Grants CAP project 2011-68002-30029 from the United States Department of Agriculture National Institute of Food and Agriculture and the Lieberman-Okinow Endowment at the University of Minnesota. X. Wang performed SNP mapping and developed and performed the Rpg5 genesilencing experiments. J. Richards developed the $H v$ Rgal-silencing construct and performed all experiments with the construct. T. Gross developed the HvAdf3-silencing construct and performed all experiments with the construct. A. Druka helped in the conception of experimental design and manuscript preparation. A. Kleinhofs helped in the conception of experimental design and manuscript preparation. B. Steffenson developed the experimental design for stem rust evaluations and performed the analysis and interpretation of phenotyping data. M. Acevedo developed the experimental design for stem rust evaluations and performed the analysis and interpretation of phenotyping data. R. Brueggeman developed the experimental design and analyzed and interpreted data. X. Wang and R. Brueggeman wrote the manuscript.

\section{LITERATURE CITED}

Ashikawa, I., Hayashi, N., Yamane, H., Kanamori, H., Wu, J., Matsumoto, T., Ono, K., and Yano, M. 2008. Two adjacent nucleotide-binding site- 
leucine-rich repeat class genes are required to confer Pikm-specific rice blast resistance. Genetics 180:2267-2276.

Birker, D., Heidrich, K., Takahara, H., Narusaka, M., Deslandes, L., Narusaka, Y., Reymond, M., Parker, J. E., and O'Connell, R. 2009. A locus conferring resistance to Colletotrichum higginsianum is shared by four geographically distinct Arabidopsis accessions. Plant J. 60:602613

Block, A., and Alfano, J. R. 2011. Plant targets for Pseudomonas syringae type III effectors: Virulence targets or guarded decoys? Curr. Opin. Microbiol. 14:39-46.

Borovkova, I. G., Steffenson, B. J., Jin, Y., Rasmussen, J. B., Kilian, A., Kleinhofs, A., Rossnagel, B. G., and Kao, K. N. 1995. Identification of molecular markers linked to the stem rust resistance gene rpg4 in barley. Phytopathology 85:181-185.

Brueggeman, R., Rostoks, N., Kudrna, D., Kilian, A., Han, F., Chen, J. Druka, A., Steffenson, B., and Kleinhofs, A. 2002. The barley stem rustresistance gene Rpgl is a novel disease-resistance gene with homology to receptor kinases. Proc. Natl. Acad. Sci. U.S.A. 99:9328-9333.

Brueggeman, R., Druka, A., Nirmala, J., Cavileer, T., Drader, T., Rostoks, N., Mirlohi, A., Bennypaul, H., Gill, U., Kudrna, D., Whitelaw, C., Kilian, A., Han, F., Sun, Y., Gill, K., Steffenson, B., and Kleinhofs, A. 2008. The stem rust resistance gene Rpg5 encodes a novel protein with nucleotide binding site, leucine-rich and protein kinase domains. Proc. Natl. Acad. Sci. U.S.A. 105:14970-14975.

Brueggeman, R., Steffenson, B. J., and Kleinhofs, A. 2009. The rpg4/Rpg5 stem rust resistance locus in barley; resistance genes and cytoskeleton dynamics. Cell Cycle 8:977-981.

Caplan, J., Padmanabhan, M., and Dinesh-Kumar, S. P. 2008 Plant NBLRR immune receptors: From recognition to transcriptional reprogramming. Cell Host Microbe 3:126-135.

Chai, Y. 2011. Investigations on stem rust resistance genes in barley. M.S thesis, University of Minnesota, St. Paul.

Chen, Y., Cheung, A. Y., and Wu, H. M. 2003. Actin-depolymerizing factor mediates Rac/Rop GTPase-regulated pollen tube growth. Plant Cell 15:237-249.

Deslandes, L., Olivier, J., Peeters, N., Feng, D. X., Khounlotham, M., Boucher, C, Somssich, I., Genin, S., and Marco, Y. 2003. Physical interaction between RRS1-R, a protein conferring resistance to bacterial wilt, and PopP2, a type III effector targeted to the plant nucleus. Proc. Natl. Acad. Sci. U.S.A. 100:8024-8029.

Dodds, P. N., Lawrence, G. J., Catanzariti, A.-M., The, T., Wang, C.-I. A., Ayliffe, M., Kobe, B., and Ellis, J. G. 2006. Direct protein interaction underlies gene-for-gene specificity and co-evolution of the flax resistance genes and flax rust avirulence genes. Proc. Natl. Acad. Sci. U.S.A. 103:8888-8893.

Druka, A., Kudrna, D., Han, F., Kilian, A., Steffenson, B., Frisch, D., Tomkins, J., Wing, R., and Kleinhofs, A. 2000. Physical mapping of barley stem rust resistance gene rpg4. Mol. Gen. Genet. 264:283-290.

Eitas, T. K., and Dangl, J. L. 2010. NB-LRR proteins: Pairs, pieces, perception, partners, and pathways. Curr. Opin. Plant Biol. 13:472-477.

Faris, J. D., Zhang, Z., Lu, H., Lu, S., Reedy, L., Cloutier, S., Fellers, J. P., Meinhardt, S. W., Rasmussen, J. B., Xu, S. S., Oliver, R. P., Simons, K. J., and Friesen, T. L. 2010. A unique wheat disease resistance-like gene governs effector-triggered susceptibility to necrotrophic pathogens. Proc. Natl. Acad. Sci. U.S.A. 107:13544-13549.

Feng, Y., Liu, Q., and Xue, Q. 2006. Comparative study of rice and Arabidopsis actin-depolymerizing factors gene families. J. Plant Physiol. 163:69-79.

Flor, H. H. 1971. Current status of the gene-for-gene concept. Annu. Rev. Phytopathol. 9:275-296.

Fu, D., Uauy, C., Distelfeld, A., Blechl, A., Epstein, L., Chen, X., Sela, H., Fahima, T., and Dubcovsky, J. 2009. A kinase-START gene confers temperature-dependent resistance to wheat stripe rust. Science 323:1357-1360.

Hanks, S., Quinn, A., and Hunter, T. 1988. The protein kinase family: Conserved features and deduced phylogeny of the catalytic domains. Science 241:42-52.

Hein, I., Barciszewska-Pacak, M., Hrubikova, K., Williamson, S., Dinesen, M., Soenderby, I., Sundar, S., Jarmolowski, A., Shirasu, K., and Lacomme, C. 2005. Virus-induced gene silencing-based functional characterization of genes associated with powdery mildew resistance in barley. Plant Physiol. 138:2155-2164.

Holzberg, S. S., Brosio, P., Gross, C., and Pogue, G. P. 2002. Barley Stripe Mosaic Virus-induced gene silencing in monocot plant. Plant J. 30:315-

Hulbert, S. H., Webb, C. A., Smith, S. M., and Sun, Q. 2001. Resistance gene complexes: Evolution and utilization. Annu. Rev. Phytopathol. 39:285-312.

Jia, J., McAdams, S. A., Bryan, G. T., Hershey, H. P., and Valent, B. 2000 Direct interaction of resistance gene and avirulence gene products con- fers rice blast resistance. EMBO (Eur. Mol. Biol. Organ.) J. 19:40044014

Jin, Y., Steffenson, B. J., and Fetch, T. G. J. 1994a. Sources of resistance to pathotype QCC of Puccinia graminis f. sp. tritici in barley. Crop Sci. 34:285-288.

Jin, Y., Steffenson, B. J., and Miller, J. D. 1994b. Inheritance of resistance to pathotypes QCC and MCC of Puccinia graminis f. sp. tritici in barley line Q21861 and temperature effects on the expression of resistance. Phytopathology 84:452-455.

Kleinhofs, A., Brueggeman, R., Nirmala, J., Zhang, L., Mirlohi, A., Druka, A., Rostoks, N., and Steffenson, B. J. 2009 Barley stem rust resistance genes: Structure and function. Plant Genome 2:109-120.

Kwon, C., Bednarek, P., and Schulze-Lefert, P. 2008. Secretory pathways in plant immune responses. Plant Physiol. 147:1575-1583.

Lee, S.-K., Song, M.-Y., Seo, Y.-S., Kim, H.-K., Ko, S., Cao, P.-J., Suh, J.P., Yi, G., Roh, J.-H., Lee, S., An, G., Hahn, T.-R., Wang, G.-L., Ronald, P., and Jeon, J.-S. 2009. Rice Pi5-mediated resistance to Magnaporthe oryzae requires the presence of two coiled-coil-nucleotide-bindingleucine-rich repeat genes. Genetics 181:1627-1638.

Leister, D. 2004. Tandem and segmental gene duplication and recombination in the evolution of plant disease resistance genes. Trends Gene 20:116-122.

Loutre, C., Wicker, T., Travella, S., Galli, P., Scofield, S., Fahima, T. Feuillet, C., and Keller, B. 2009. Two different CC-NBS-LRR genes are required for Lr10-mediated leaf rust resistance in tetraploid and hexaploid wheat. Plant J. 60:1043-1054.

Martin, G. B., Brommonschenkel, S. H., Chunwongse, J., Frary, A., Ganal, M. W., Spivey, R., Wu, T., Earle, E. D., and Tanksley, S. D. 1993. Mapbased cloning of a protein kinase gene conferring disease resistance in tomato. Science 262:1432-1436.

Martin, G. B, Bogdanove, A. J., and Sessa, G. 2003. Understanding the function of plant disease resistance proteins. Annu. Rev. Plant Biol. 54:23-61.

Meyers, B. C., Kozik, A., Griego, A., Kuang, H. H., and Michelmore, R. W. 2003 Genome-wide analysis of NBS-LRR-encoding genes in Arabidopsis. Plant Cell 15:809-834.

Miklis, M., Consonni, C., Bhat, R. A., Lipka, V., Schulze-Lefert, P., and Panstruga, R. 2007. Barley $M L O$ modulates actin-dependent and actinindependent antifungal defense pathways at the cell periphery. Plant Physiol. 144:1132-1143.

Moscou, M. J., Lauter, N., Steffenson, B., and Wise, R. P. 2011 Quantitative and qualitative stem rust resistance factors in barley are associated with transcriptional suppression of defense regulons. PLoS Genet. 7:e1002208.

Narusaka, M., Shirasu, K., Noutoshi, Y., Kubo, Y., Shiraishi, T., Iwabuchi, M., and Narusaka, Y. 2009 RRS1 and RPS4 provide a dual resistancegene system against fungal and bacterial pathogens. Plant J. 60:218-226.

Nirmala, J., Drader, T., Chen, X., Steffenson, B., and Kleinhofs, A. 2010 Stem rust spores elicit rapid RPG1 phosphorylation. Mol. PlantMicrobe Interact. 23:1635-1642.

Okuyama, Y., Kanzaki, H., Abe, A., Yoshida, K., Tamiru, M., Saitoh, H., Fujibe, T., Matsumura, H., Shenton, M., Galam, D. C. Undan, J., Ito, A., Sone, T., and Terauchi, R. 2011. A multi-faceted genomics approach allows the isolation of rice Pia-blast resistance gene consisting of two adjacent NBS-LRR protein genes. Plant J. 66:467-479.

Ouellet, F., Carpentier, E., Cope, J., Monroy, A.F., and Sarhan, F. 2001 Regulation of a wheat actin-depolymerizing factor during cold acclimation. Plant Physiol. 125:360-368.

Park, C.-J., Peng, Y., Chen, X., Dardick, C., Ruan, D., Bart, R., Canlas, P. E., and Ronald, P. E. 2008. Rice XB15, a protein phospahatase 2C, negatively regulates cell death and XA21-mediated innate immunity. PLoS Biol. 6:e231.

Peart, J. R., Mestre, P., Lu, R., Malcuit, I., and Baulcombe, D. C. 2005. NRG1, a CC-NB-LRR protein, together with N, a TIR-NB-LRR protein, mediates resistance against tobacco mosaic virus. Curr. Biol. 15:968-973.

Pretorius, Z. A., Singh, R. P., Wagoire, W. W., and Payne, T. S. 2000. Detection of virulence to wheat stem rust resistance gene $\mathrm{Sr} 31$ in Puccinia graminis. f. sp. tritici in Uganda. Plant Dis 84:203.

Roelfs, A. P., Casper, D. H., Long, D. L., and Roberts, J. J. 1991. Races of Puccinia graminis in the United States in 1989. Plant Dis 75:11271130.

Rostoks, N., Schmierer, D., Kudrna, D., and Kleinhofs, A. 2003. Barley putative hypersensitive induced reaction genes: Genetic mapping, sequence analyses and differential expression in disease lesion mimic mutants. Theor. Appl. Genet. 107:1094-1101.

Scofield, S. R., Huang, L., Brandt, A. S., and Gill, B. S. 2005. Development of a virus-induced gene silencing system for hexaploid wheat and its use in functional analysis of LR21-mediated leaf rust resistance pathway. Plant Physiol. 138:2165-2173. 
Shao, F., Golstein, C., Ade, J., Stoutemyer, M., Dixon, J. E., and Innes, R. W. 2003. Cleavage of Arabidopsis PBS1 by a bacterial type III effector. Science 301:1230-1233.

Sinapidou, E., Williams, K., Nott, L., Bahky, S., Tor, M., Bittner-Eddy, P., and Beynon, J. 2004. Two TIR:NB:LRR genes are required to specify resistance to Peronospora parasitica isolate Cala2 in Arabidopsis. Plant J. 38:898-909.

Singh, R. P., Hodson, D. P., Huerta-Espino, J., Jin, Y., Njau, P., Wanyera, R., Herrera-Foessel, S. A., and Ward, R. W. 2008. Will stem rust destroy the world's wheat crop? Adv. Agron. 98:271-309.

Song, W.-Y., Wang, G.-L., Chen, L., Kim, H.-S., Pi, L.-Y., Gardner, J., Wang, B., Holsten, T., Zhai, W.-X., Zhu, L.-H., Fauquet, C., and Ronald, P. C. 1995. A receptor kinase-like protein encoded by the rice disease resistance gene, $\mathrm{Xa21}$. Science 270:1804-1806.

Stakman, E. C., Stewart, D. M., and Loegering, W. Q. 1962. Identification of physiological races of Puccinia graminis f. sp. tritici. U.S. Dep. Agric. Agric. Res. Serv. Publ. No. E617.

Steffenson, B. J. 1992. Analysis of durable resistance to stem rust in barley. Euphytica 63:153-167.

Steffenson, B. J., and Jin, Y. 2006. Resistance to race TTKS of Puccinia graminis f. sp. tritici in barley. (Abstr.) Phytopathology 96:S110.

Steffenson, B. J., Jin, Y., Brueggeman, R. S., Kleinhofs, A., and Sun, Y. 2009. Resistance to stem rust race TTKSK maps to the rpg4/Rpg5 complex of chromosome 5H of barley. Phytopathology 99:1135-1141.

Steffenson, B. J., Zhou, H., Chai, Y., and Grando, S. 2012. Vulnerability of cultivated and wild barley to African stem rust race TTKSK. Pages 149155 in: Advances in Barley Science: Proc. 11th Int. Barley Genet. Symp. C. Li, G. Zhang, and X. Liu, eds. Zhejiang University Press, Hangzhou, China.

Sun, X., Cao, Y., Yang, Z., Xu, C., Li, X., Wang, S., and Zhang, Q. 2004. Xa26, a gene conferring resistance to Xanthomonas oryzae pv. oryzae in rice, encodes an LRR receptor kinase-like protein. Plant J. 37:517527.

Sun, Y., and Steffenson, B. J. 2005. Reaction of barley seedlings with different stem rust resistance genes to Puccinia graminis $\mathrm{f}$. sp. tritici and Puccinia graminis f. sp. secalis. Can. J. Plant Pathol. 27:80-89.

Sun, Y., Steffenson, B. J., and Jin, Y. 1996. Genetics of resistance to Puccinia graminis f. sp. secalis in barley line Q21861. Phytopathology 86:1299-1302.

Swiderski, M. R., and Innes, R. W. 2001. The Arabidopsis PBS1 resistance gene encodes a member of a novel protein kinase subfamily. Plant J. 26:101-112.
Tang, X., Frederick, R. D., Zhou, J., Halterman, D. A., and Yia, Y. 1996. Initiation of plant disease resistance by physical interaction of AvrPto and Pto kinase. Science 274:2060-2063.

Thomas, P., and Schiefelbein, J. 2002. Cloning and characterization of an actin depolymerizing factor gene from grape (Vitis vinifera L.) expressed during rooting in stem cuttings. Plant Sci. 162:283-288.

Tian, M., Chaudhry, F., Ruzicka, D. R., Meagher, R. B., Staiger, C. J., and Day, B. 2009. Arabidopsis actin-depolymerizing factor AtADF4 mediates defense signal transduction triggered by the Pseudomonas syringae effector AvrPphB. Plant Physiol. 150:815-824.

Tufan, H. A., Stefanato, F. L., McGrann, G. R. D., MacCormack, R., and Boyd, L. A. 2011. The Barley Stripe Mosaic Virus system used for virus-induced gene silencing in cereals differentially affects susceptibility to fungal pathogens in wheat. J. Plant Physiol. 168:990-994.

Ueda, H., Yamaguchi, Y., and Sano, H. 2006. Direct interaction between the tobacco mosaic virus helicase domain and the ATP-bound resistance protein, $\mathrm{N}$ factor during the hypersensitive response in tobacco plants. Plant Mol. Biol. 61:31-45.

Van Der Biezen, E. A., and Jones, J. D. G. 1998. Plant disease-resistance proteins and the gene-for-gene concept. Trends Biochem. Sci. 23):454456.

Van Der Hoom, R. A. L., and Kamoun, S. 2008. From Guard to Decoy: A New Model for perception of plant pathogen effectors. Plant Cell 20:2009-2017.

Yu, Y., Tomkins, J., Waugh, R., Frisch, D., Kudrna, D., Kleinhofs, A., Brueggeman, R., Muehlbauer, G., Wise, R., and Wing, R. 2000. A bacterial artificial chromosome library for barley (Hordeum vulgare L.) and the identification of clones containing putative resistance genes Theor. Appl. Genet. 101:1093-1099.

Yuan, B., Zhai, C., Wang, W., Zeng, X., Xu, X., Hu, H., Lin, F., Wang, L., and Pan, Q. 2011. The Pik-p resistance to Magnaporthe oryzae in rice is mediated by a pair of closely linked CC-NBS-LRR genes. Theor. Appl. Genet. 122:1017-1028.

Zhou, T., Wang, Y., Chen, J. Q., Araki, H., Jing, Z., Jiang, K., Shen, J., and Tian, D. 2004. Genome-wide identification of NBS genes in japonica rice reveals significant expansion of divergent non-TIR NBS-LRR genes. Mol. Genet. Genomics 271:402-415.

\section{AUTHOR-RECOMMENDED INTERNET RESOURCE}

The harvEST database: www.harvest-web.org 